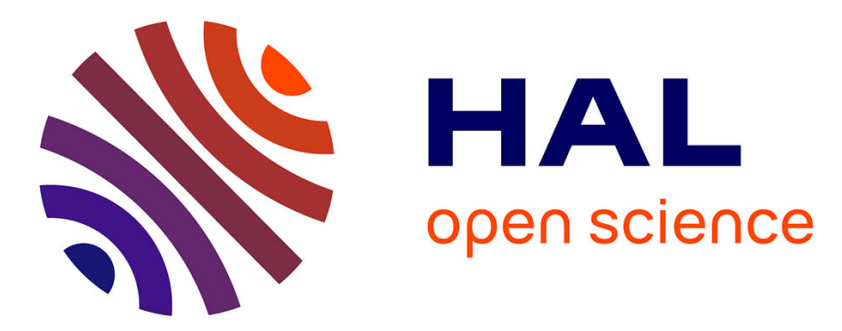

\title{
Effect of seasonal dynamics of vegetation cover on land surface models: a case study of NOAH LSM over a savanna farm land in eastern Burkina Faso, West Africa F. Bagayoko, S. Yonkeu, N. C. van de Giesen
}

\section{- To cite this version:}

F. Bagayoko, S. Yonkeu, N. C. van de Giesen. Effect of seasonal dynamics of vegetation cover on land surface models: a case study of NOAH LSM over a savanna farm land in eastern Burkina Faso, West Africa. Hydrology and Earth System Sciences Discussions, 2006, 3 (5), pp.2757-2788. hal-00298766

\author{
HAL Id: hal-00298766 \\ https://hal.science/hal-00298766
}

Submitted on 12 Sep 2006

HAL is a multi-disciplinary open access archive for the deposit and dissemination of scientific research documents, whether they are published or not. The documents may come from teaching and research institutions in France or abroad, or from public or private research centers.
L'archive ouverte pluridisciplinaire HAL, est destinée au dépôt et à la diffusion de documents scientifiques de niveau recherche, publiés ou non, émanant des établissements d'enseignement et de recherche français ou étrangers, des laboratoires publics ou privés. 
Hydrol. Earth Syst. Sci. Discuss., 3, 2757-2788, 2006 www.hydrol-earth-syst-sci-discuss.net/3/2757/2006/

(C) Author(s) 2006. This work is licensed under a Creative Commons License.
Hydrology and Earth System Sciences Discussions

Papers published in Hydrology and Earth System Sciences Discussions are under open-access review for the journal Hydrology and Earth System Sciences

Effect of seasonal dynamics of vegetation cover on land surface models: a case study of NOAH LSM over a savanna farm land in eastern Burkina Faso, West Africa

F. Bagayoko ${ }^{1,2}$, S. Yonkeu ${ }^{3}$, and N. C. van de Giesen ${ }^{1,2}$

${ }^{1}$ Water Resources Management, Faculty of Civil Engineering and Geosciences, TU Delft, Stevinweg 1, 2600 GA Delft, P.O. Box 5048, The Netherlands

${ }^{2}$ Center for Development Research (ZEF), University of Bonn, Walter-Flex Str. 3, 53113 Bonn, Germany

${ }^{3}$ Groupe EIER-ETSHER, 03 BP 7023 Ouagadougou 03, Burkina Faso

Received: 16 January 2006 - Accepted: 10 March 2006 - Published: 12 September 2006

Correspondence to: N. C. van de Giesen (n.c.vandegiesen@ citg.tudelft.nl)

HESSD

3, 2757-2788, 2006

Seasonal dynamics of vegetation covers and land surface models

F. Bagayoko et al.

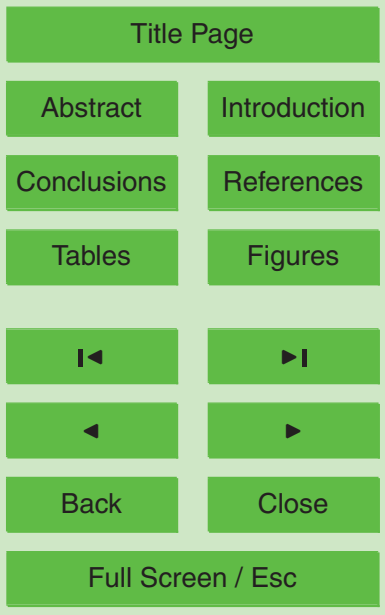

Printer-friendly Version

Interactive Discussion 


\section{Abstract}

The sensitivity of the land surface model of the National Centers for Environmental Prediction (NCEP), the Oregon State University, the Air Force and the Hydrologic Research Lab (NOAH LSM) was evaluated with respect to the seasonal dynamics of the 5 vegetation cover in the savanna area under intensive agriculture in the eastern part of Burkina Faso, West Africa. The data collected during the first long-term measurement of the surface fluxes in this mentioned region was used for this purpose. The choice of NOAH LSM was motivated by the fact that it has already been tested in different environments in West Africa, especially in Ghana.

The sensitivity was tested by comparing the simulated surfaces fluxes using a fixed values of the roughness length for momentum as a standard in the model and the true seasonal value of this variable. The results show that NOAH LSM was not sensitive to the change of the roughness length for momentum neither on a seasonal basis nor on a daily basis, which was found to be abnormal. The formulation of the coefficient

$15\left(B_{C}\right)$ coupling the dry canopy transpiration to the atmosphere was found to be the main reason for this. An improved formulation for this coefficient was given to solve this insensitivity and to improve the performance of the model. Recommendations are also given to enhance the performance of the model in the West African savanna environment.

\section{Introduction}

The performance of most of the Land Surface Models (LSM) is particularly sensitive to the partitioning of the energy on the earth's surface. The LSMs fail when simulating the real seasonal dynamics of the surface fluxes over the semi-arid terrain, especially over the savanna vegetation in West Africa (Schüttemeyer, 2005). The reason for this failure is that the LSMs are mostly calibrated for temperate regions (midlatitudinal region) where the feedback mechanisms in the boundary layer are more related to the
HESSD

3, 2757-2788, 2006

\section{Seasonal dynamics of vegetation covers and land surface models}

F. Bagayoko et al.

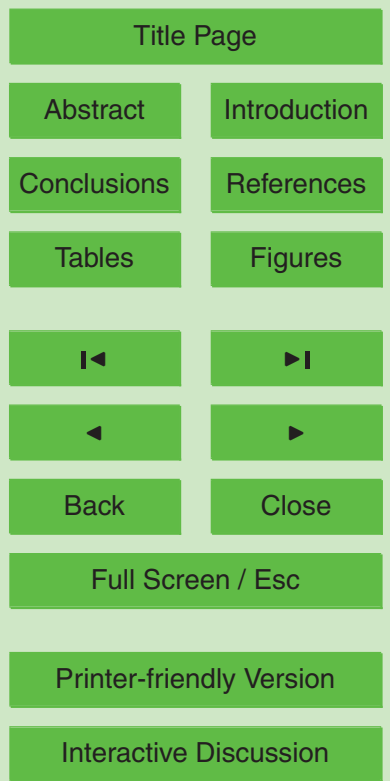

EGU 
soil wetness, whereas in semi-arid regions this feedback is related to the way stomata release water into the atmosphere (Niyogi et al., 2002; Schüttemeyer, 2005). Another reason is that when these models are based on data of the semi-arid regions, the relatively short observation time leads to a partial modeling or insight of the process of 5 the dynamics of the surface fluxes. An illustration of this situation is the HAPEX-Sahel project (Goutorbe et al., 1994) and the SEBEX project (Sellers et al., 1997). The first project lasted for only three months of intensive observation of the surface fluxes.

In fact, the savanna region is one of the most sensitive areas in the world because of the climate pattern. This region is characterised by a relative short rainy season 10 (May to October) followed by a long dry season (November to April), which implies a complete change in the soil moisture conditions and the morphology of the vegetation. During the rainy season, the LSMs accurately estimate the surface fluxes, because the soil wetness is similar to that in the midlatitudinal regions. At the end of the rainy season, the environment starts to dry out and this drying period is not taken into account in most of the models. Schüttemeyer (2005) tested the NOAH LSM model in two different regions in Ghana, West Africa, and concluded that the mean bias error increased during the drying period due to the use of wrong values of surface albedo, temperature, leaf area index $(L A /)$ and the Zilintekinvich coefficient. The NOAH LSM is a joint product of the National Centers for Environmental Prediction (NCEP), the Oregon

State University, the Air Force and the Hydrologic Research Lab and is based on the former Oregon State University land surface model (OSULSM) (Ek and Mahrt, 1991). Schüttemeyer (2005) modified the equation employed in the model for the estimation of the surface resistance, to adjust it to a real situation of savanna vegetation for the drying period.

25 Another important parameter affecting the accuracy of the NOAH LSM is the ratio $z_{0 m} / z_{0 h}$ (roughness length for momentum over the roughness length for heat). Authors use a fixed value for this ratio, which could be one for the reasons of its failure to simulate accurately the surface fluxes over the savanna vegetation of West Africa. In fact, the roughness length for momentum is not constant over time and variation is more
HESSD

3, 2757-2788, 2006

\section{Seasonal dynamics of vegetation covers and land surface models}

F. Bagayoko et al.

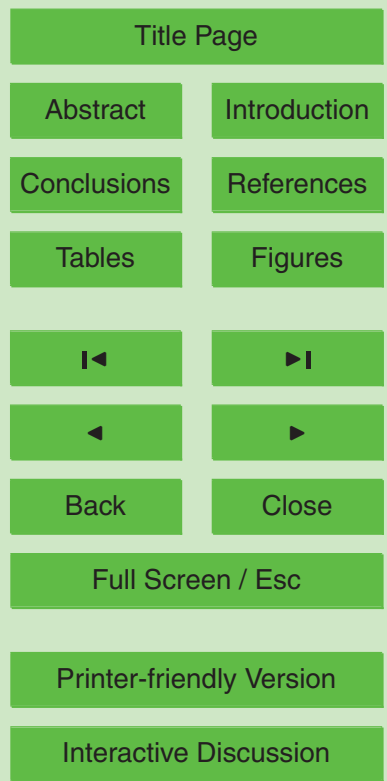


pronounced over a terrain under intensive agriculture because of the large change in the vegetation fraction and $L A /$ according to season. A seasonal bush fire, especially during the dry season, also changes this variable in areas without any agricultural activities. Therefore, the objective of this study is to evaluate and to test the sensitivity 5 of the LSMs to the dynamics of the vegetation cover with respect to $z_{0 m}$. The NOAH LSM is used for this purpose because it constitutes a typical LSM, which couples the soil and the vegetation to the atmosphere by the surface exchange coefficient for heat $\left(C_{h}\right)$. The sensitivity of the NOAH LSM with respect to $z_{0 m}$ could illustrate the behavior of most of the LSMs, because they all have a similar conception. First, the standard 10 form of NOAH LSM (fixed value of $z_{0 m}$ for all periods) was evaluated and, the result then compared the result to the one using the season-dependent values of $z_{0 m}$ calculated from the data collected in Kompienga (East Burkina Faso: $11^{\circ} 07^{\prime} \mathrm{W} ; 0^{\circ} 31^{\prime} \mathrm{E}$ ) from May 2003 to November 2004. The results cover almost two years, including one relatively wet (2003) and one relatively dry (2004) year. They can contribute to obtaining more 15 insight and to better understanding of the real dynamics of the surface fluxes, and to refining the land surface models in this environment. The research was conducted within the framework of the GLOWA-Volta (van de Giesen et al., 2002) and VinVal projects.

\section{Model description}

20 The NOAH LSM model is based on the principle of the NCEP meso-scale evaporation model. There are two major concepts: the multi-layer soil and the simple canopy layer concept. The multi-layer soil concept is based on the model of Mahrt and Pan (1984), and the moisture used for the canopy transpiration is extracted from the different layers using a weighting function including the root depth and a uniform root distribution. The

Fourier law of diffusion. The surface skin temperature is determined following Mahrt and Ek (1984) by applying a single linear surface energy balance equation representing
HESSD

3, 2757-2788, 2006

\section{Seasonal dynamics of vegetation covers and land surface models}

F. Bagayoko et al.

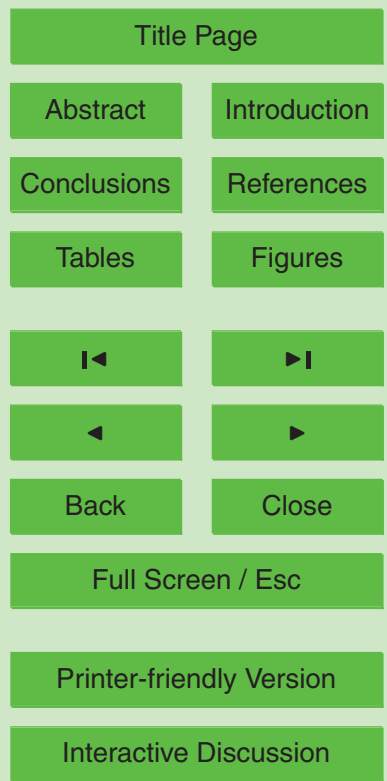

EGU 
the combined ground/vegetation surface. The canopy layer concept is based on the model of Pan and Mahrt (1987), which has been extended by Chen et al. (1996) to include the complex canopy resistance approach of Noilhan et Planton (1989) and Jacquemin and Noilhan (1990). This is an empirically based approach for canopy 5 resistance following the original model of Jarvis (1976) and Stewart (1996).

The subgrid variability is taken into account with a Reynold's number-dependent formulation for the ratio of roughness length for momentum $\left(z_{0 m}\right)$ [m] and heat $\left(z_{0 h}\right)[\mathrm{m}]$. The formulation proposed by Zilitinkevich (1995) is used in NOAH and is expressed as follows:

$k B^{-1}=\ln \left(\frac{z_{0 m}}{z_{0 h}}\right)$

with

$B^{-1}=C \sqrt{R e^{*}}$ and $R e^{*}=\frac{u^{*} z_{0 m}}{v}$

where $k$ is the von Kármán constant $(k=0.41), v$ is the kinematic molecular viscosity $(-), R e^{*}$ is the roughness Reynolds number $\left[\mathrm{m}^{2} \mathrm{~s}^{-1}\right], u^{*}$ is the friction velocity $\left[\mathrm{m} \mathrm{s}^{-1}\right]$, 15 and $C$ is the coefficient ranging from 0.2 to 0.4 . According to Schüttemeyer (2005), a value of $C=0.6$ is suitable for the savanna region of West Africa.

The canopy resistance is modeled as a function of the atmospheric forcing and the soil moisture availability. The total evaporation $(E)$ is the sum of the direct evaporation from the bare soil $\left(E_{b}\right)[\mathrm{mm}]$, the wet canopy evaporation $\left(E_{c}\right)[\mathrm{mm}]$ and the dry canopy transpiration $\left(E_{t}\right)[\mathrm{mm}] . E_{b}$ is calculated as follows:

$E_{b}=\left(1-\alpha_{V}\right) \beta_{b} E_{p}$

with

$\beta_{b}=\frac{\Theta_{1}-\Theta_{w p}}{\Theta_{f c}-\Theta_{w p}}$

Title Page

HESSD

3, 2757-2788, 2006

Seasonal dynamics of vegetation covers and land surface models

F. Bagayoko et al.

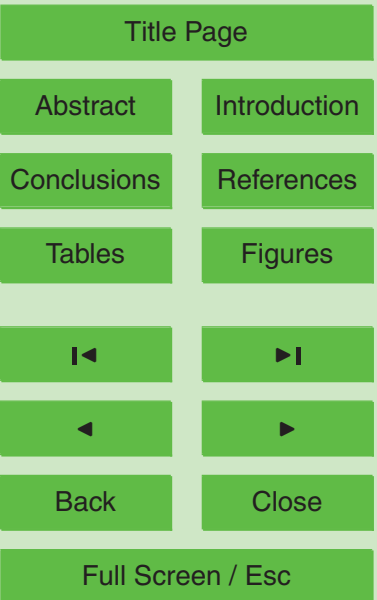

Printer-friendly Version

Interactive Discussion 
where $E_{p}$ is the potential evaporation [mm] calculated based on Mahrt and Ek (1984). $\Theta_{f c}$ and $\Theta_{w p}$ are the soil water content at field capacity and wilting point, respectively. $\alpha_{V}$ is the green vegetation fraction for the partitioning of the total evapotranspiration.

The evaporation of the water intercepted by the canopy is computed as follows:

$3,2757-2788,2006$

${ }_{5} E_{c}=\alpha_{V} E_{p}\left(\frac{W_{c}}{S}\right)^{n}$

where $W_{c}$ is the intercept canopy water content $(\mathrm{mm}), S$ is the maximum allowed $W_{c}$ capacity $\left(W_{c}=0.5 \mathrm{~mm}\right)$, and $n=0.5$.

The dry canopy transpiration is determined by:

$E_{t}=\alpha_{V} E_{p} B_{c}\left[1-\left(\frac{W_{c}}{S}\right)^{n}\right]$

10 with

$B_{C}=\frac{1+\frac{\Delta}{R_{r}}}{1+R_{C} C_{h}+\frac{\Delta}{R_{r}}}$

where $C_{h}$ is the surface exchange coefficient for the heat and moisture $\left[\mathrm{m} \mathrm{s}^{-1}\right], \Delta$ is the slope of the saturated specific humidity curve $\left[\mathrm{mbar} \mathrm{K}^{-1}\right], R_{r}$ is a correction coefficient and is a function of the surface air temperature $\left[\mathrm{mbar} \mathrm{K}^{-1}\right]$, the surface pressure, and ${ }_{15} C_{h}$. There are two possible formulations of $C_{h}$ (Chen et al., 1997). We present here the formulation based on the Obukhov length expressed as follows:

$C_{h}=\frac{k^{2} / R}{\left[\ln \left(\frac{z}{z_{0 m}}\right)-\psi_{m}\left(\frac{z}{L}\right)+\psi_{h}\left(\frac{z_{0 m}}{L}\right)\right] \times\left[\ln \left(\frac{z}{h_{o h}}\right)-\psi_{m}\left(\frac{z}{L}\right)+\psi_{h}\left(\frac{z_{0 h}}{L}\right)\right]}$

where $z$ is the measurement height [m], $L$ is Monin-Obukhov length [m] and $R=1.0$. $\psi_{m}$ and $\psi_{h}$ are the similarity theory-based stability functions for the momentum and

Seasonal dynamics of vegetation covers and land surface models

F. Bagayoko et al.

Title Page

Abstract Introduction

Conclusions References

Tables Figures

14

4

Back

Close

Full Screen / Esc

Printer-friendly Version

Interactive Discussion 
heat, respectively. Paulson (1970) integrated a set of analytical expressions to specify a non-dimensional wind speed and potential temperature gradients as a function of $\frac{Z}{L}$. HESSD

Following Sun and Mahrt (1995), these stability functions are expressed as follows:

$\psi_{m}= \begin{cases}-5 \xi & 0<\xi<1 \\ 2 \ln \left(\frac{1+x}{2}\right)+\ln \left(\frac{1+x^{2}}{2}\right)-2 \tan ^{-1}(x)+\frac{\pi}{2} & -5<\xi<0\end{cases}$

$\psi_{h}= \begin{cases}-5 \xi & 0<\xi<1 \\ 2 \ln \left(\frac{1+x^{2}}{2}\right) & -5<\xi<0\end{cases}$

with

$\xi=\frac{Z}{L}$ and $x=(1-16 \xi)^{1 / 4}$

$R_{c}$ is the canopy resistance and is based on the "big-leaf" approach developed by NP89 following the original approach of Jarvis (1976) and Stewart (1988). It is computed as 10 follows:

$R_{c}=\frac{R_{c \min }}{L A l \times F_{1} \times F_{2} \times F_{3} \times F_{4}}$

where

$F_{1}=\frac{R_{C \min }}{R_{C \max }+\frac{f}{1+f}}$

with

$f=0.55 \frac{R_{g}}{R_{G L}} \frac{2}{L A l}$

where $R_{c \text { min }}$ and $R_{c \text { max }}$ is the minimum and maximum canopy resistance [s $\mathrm{m}^{-1}$ ], respectively. $R_{g}$ is the global radiation at the surface [W $\left.\mathrm{m}^{-2}\right], R_{G L}$ is site dependent parameter $\left[\mathrm{W} \mathrm{m}^{-2}\right]$, and $L A /$ is leaf area index.

3, 2757-2788, 2006

\section{Seasonal dynamics of vegetation covers and land surface models}

F. Bagayoko et al.

Title Page

Abstract

Introduction

Conclusions

References

Tables

Figures

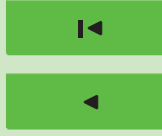

$\rightarrow 1$

Back

Close

Full Screen / Esc

Printer-friendly Version

Interactive Discussion

EGU 
$F_{2}$ is based on the new formulation of Schüttemeyer (2005) and is computed as follows:

HESSD

$F_{2}^{-1}=\exp \left(-g_{D} V P D\right)$

3, 2757-2788, 2006

where $g_{D}$ is an optimized parameter for the savanna conditions $\left[\mathrm{g} \mathrm{kg}^{-1}\right]$ and $V P D$ is 5 the air pressure deficit [mbar].

$F_{3}=1-a_{T}\left(T_{\text {ref }}-T_{a}\right)^{2}$

where $a_{T}$ is thermal coefficient, $T_{\text {ref }}$ is the reference temperature and $T_{a}$ is the air temperature $(\mathrm{C})$.

$F_{4}^{-1}= \begin{cases}0 & \varpi<\Theta_{w} \\ \frac{\varpi-\Theta_{w}}{\Theta_{\text {ref }}-\Theta_{w}} & \Theta_{w}<\varpi<\Theta_{\text {ref }} \\ 1 & \varpi>\Theta_{\text {ref }}\end{cases}$

where $\varpi=\sum_{i=1}^{Z} R_{m}, R_{m}$ is the root density $\left[\mathrm{m} \mathrm{m}^{-3}\right.$ ] calculated according to Zeng et al. (1998) and $m$ is the number of soil layers. $\Theta_{w}$ and $\Theta_{\text {ref }}$ are soil moisture at wilting point and field capacity $\left[\mathrm{m}^{-3} \mathrm{~kg}^{-1}\right]$, respectively.

The forcing data used in the model are summarized in Table 1 together with the coefficients and parameters. The vegetation type was set to savanna and the same vegetation fraction set by Schüttemeyer (2005) for Tamale was used. The soil type was set to sandy loam according to Ungaro et al. (2004). More details on the model can be found in Schüttemeyer (2005), Chang et al. (1999), and Cheng et al. (1997).

\section{Method}

The NOAH LSM was run off-line and the simulated sensible and latent heat flux were

Seasonal dynamics of vegetation covers and land surface models

F. Bagayoko et al.

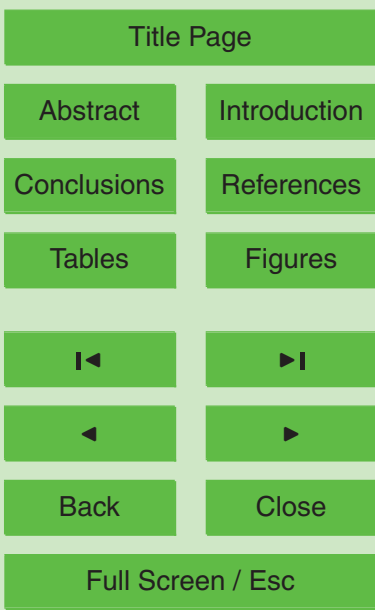

Printer-friendly Version

Interactive Discussion 
The forcing data were obtained from a nearby automatic weather station, at $2 \mathrm{~m}$ above ground surface. The sample period was $5 \mathrm{~s}$ and the average value of all variables was stored every $20 \mathrm{~min}$. The ground heat flux and net radiation were not directly measured, therefore the analysis focused on the sensible and latent heat flux on an hourly basis.

5 The time step for the integration was set to one hour. Eddy fluxes and the atmospheric forcing data were available from May 2003 to November 2004 with some gaps because of technical problems with the station. Therefore, the model was run for those periods, where data was available (the period between downloads). For each period, the model was run with a corresponding seasonal value of $z_{0 m}$ calculated according to Martano 10 (1999) with a fixed value $z_{0 m}$ as used in the standard form of NOAH LSM. This fixed value of $z_{0 m}$ was set to $0.216 \mathrm{~m}$, the average of the whole season-dependent $z_{0 \mathrm{~m}}$. The results for each run were compared on a seasonal basis, and on a daily basis for two selected periods during the drying period (DOY348 to DOY365), and the rainy season (DOY227 to DOY250). The seasonal values of $z_{0 m}$ are presented in Table 2. In order 15 to test the sensitivity of the model to the initial moisture in the soil and to canopy water content, $E_{b}$ and $E_{c}$ were neglected during the completely dry season (from December to late April), and the results were compared to the case when all components of evaporation were taken into account.

The surface downward longwave radiation was not directly measured. It was es20 timated using the air temperature and relative humidity following Idso and Jackson (1969) for clear sky conditions (see Schüttemeyer, 2005).

\section{Results and discussion}

The results from the model were compared to the observed values for sensible heat and latent heat flux on a seasonal and daily basis. The sensitivity of the model with 25

espect to the roughness length for momentum is discussed as well as the sensitivity to the initial soil moisture in the soil layer. Recommendations are given for refining the model to a savanna environment under intense agriculture.

\section{HESSD}

3, 2757-2788, 2006

\section{Seasonal dynamics of vegetation covers and land surface models}

F. Bagayoko et al.

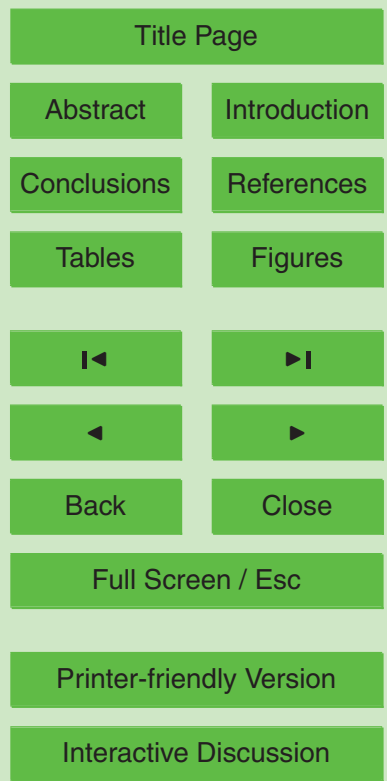

EGU 


\subsection{Comparison at seasonal basis}

\subsubsection{Latent heat flux}

$\mathrm{NOAH}$ LSM reasonably reproduces the seasonal pattern of $\lambda E$ but underestimates it most of the time as shown by the seasonal pattern of the mean bias error (MBE) 5 (Fig. 1). When a fixed value of $z_{0 m}=0.216 \mathrm{~m}$ was used for the simulation, the average MBE of $-35 \mathrm{~W} \mathrm{~m}^{-2}$ and $-40 \mathrm{~W} \mathrm{~m}^{-2}$ was obtained during the rainy season of 2003 and 2004, respectively. During the transition period (drying up and wetting periods), the average $\mathrm{MBE}$ was $-5 \mathrm{Wm}^{-2}$. Similarly, during the dry period the average MBE was $-19 \mathrm{~W} \mathrm{~m}^{-2}$. The absolute value of the MBE is relatively important during the rainy 10 season in contrast to the transition period (drying and wetting period). The model underestimates $\lambda E$ in the rainy season and might be related to the measurement device. In fact, in eddy covariance systems, air moisture content is measured with a Krypton hygrometer, which has a pathway of $1 \mathrm{~cm}$ between the lenses. Sometimes, under rainy conditions, the lenses can be wetted completely by rain drops, which can lead to an overestimation of $\lambda E$. Likewise, dew can cause a similar effect and can also lead to an overestimation of $\lambda E$. This fact becomes clear when $\lambda E$ is analyzed on a daily basis (see Sect. 4.2.1). The weakness of the MBE in the transition periods might be related to the modification by Schüttemeyer (2005), who adjusted the estimation of the surface resistance to the climatic conditions of the West African savanna during those periods. However, as the work of Schüttemeyer was limited to only one drying period (from August 2003 to January 2003), the improvement seems to be limited to that period and does not take into account the situation during the dry period (January to April), where the MBE increased again. When all components of the evaporation where taken into account, the model led to an overestimation of about $58 \%$ of the observed $\lambda E$ in December (DOY348 to DOY365). Similar observations were found on a daily basis for the same period, where the MBE was $34 \mathrm{~W} \mathrm{~m}^{-2}$ (see Sect. 4.3). Similarly, the model overestimated the observed $\lambda E$ by $38 \%$ between January and February. This observation

\section{Seasonal dynamics of vegetation covers and land surface models}

F. Bagayoko et al.

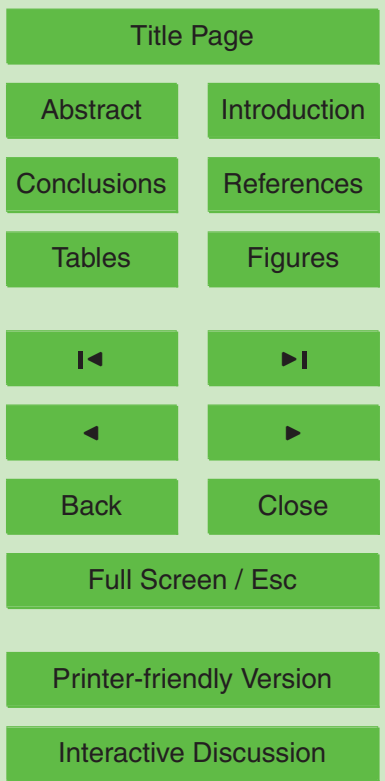


seems to be related to the static treatment of the initial moisture conditions in the soil layer. Ek and Holtslag (2004) came to similar conclusions in their study at Cabauw, Netherlands. According to those authors, a change of moisture in the soil layer by a few percent can have a notable effect on the surface fluxes, i.e. on observed as well 5 as modeled. Therefore, more attention should be given to soil moisture conditions. Instead of a static treatment, a seasonal pattern should be taken into account to reduce this error.

When the analysis using the seasonal values of $z_{0 m}$, was repeated a relatively weak improvement of the absolute MBE during the rainy and dry season $\left(-28 \mathrm{~W} \mathrm{~m}^{-2}\right.$ and $10-37 \mathrm{~W} \mathrm{~m}^{-2}$ during the rainy season of 2003 and 2004 , respectively, and $-16 \mathrm{~W} \mathrm{~m}^{-2}$ during the dry season) was obtained. In contrast, the absolute value of the MBE increaed during the transition periods $\left(\mathrm{MBE}=-9 \mathrm{~W} \mathrm{~m}^{-2}\right)$. Therefore, it can be conclude that, the simulation of $\lambda E$ was not very sensitive to the change in $z_{0 m}$ on a seasonal basis.

\subsubsection{Sensible heat flux}

A similar analysis for the case of $\lambda E$ was performed. In the simulation, a fixed value of $z_{0 m}=0.216 \mathrm{~m}$ was first used and then a season-dependent value corresponding to each period. As shown in Fig. 2, the simulated $H$ fits the observed $H$ quite well. The MBE is low during the rainy season for both cases with an overall underestimation during 20 the rainy season of 2003 (MBE of $-0.82 \mathrm{~W} \mathrm{~m}^{-2}$ and $-1.6 \mathrm{~W} \mathrm{~m}^{-2}$ in the case of a fixed value of $z_{0 m}$ and a seasonal value of $z_{0 m}$, respectively). Similarly, the model led to an overall overestimation during the rainy season of 2004. This underestimation in 2003 and the overestimation in 2004 could be related to the distribution of the rainfall during both rainy seasons. In fact, during the rainy season of 2003, the rainfall was distributed reflected the real situation in the field. In contrast, rainfall was very irregular during the rainy season of 2004, so that the surface albedo and the vegetation fraction changed appreciably between the two rainfall events. Therefore the value of the surface albedo

\section{HESSD}

3, 2757-2788, 2006

\section{Seasonal dynamics of vegetation covers and land surface models}

F. Bagayoko et al.

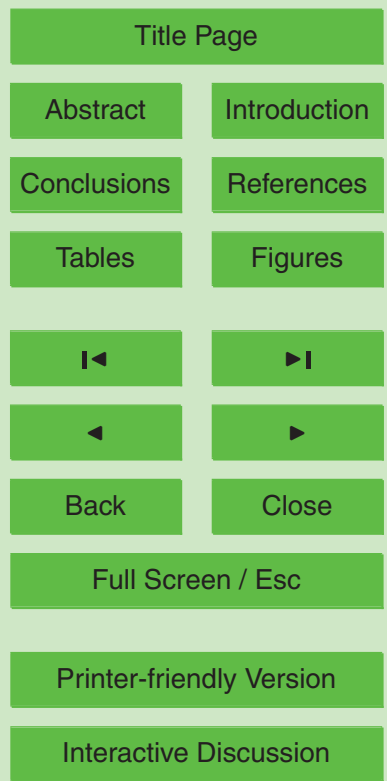

EGU 
and the vegetation fraction may not reflect the real field conditions.

The model also underestimated the observed $H$ between October and November 2003 corresponding to the beginning of the drying period (Fig. 2) and might be related to use of incorrect surface albedo and the vegetation fraction value. In the drying and 5 the completely dry period, the model led to an overall overestimation of the sensible heat flux (MBE $=4 \mathrm{~W} \mathrm{~m}^{-2}$ for both cases). This overestimation could also be related to the incorrect value of the surface albedo, the vegetation fraction and the coefficient of Zilitinkevich, which have a direct effect on sensible heat flux, net radiation and latent heat flux trhough the calculation of the ratio $z_{0 m} / z_{0 h}$. Therefore, the simultaneous 10 analysis of these three variables could be a first step in understanding this process (Schüttemeyer, 2005). In fact, these three variables are related to each other according to the principle of the energy balance closure.

Here, it was also observed that the use of the seasonal value of $z_{0 m}$ does not have a strong effect on the simulation of the sensible heat flux. However, $z_{0 m}$ becomes more 15 relevant when analyzing $L E$ and $H$ on a daily basis. This is the focus of Sect. 4.2.

\subsection{Comparison at daily basis (drying period)}

\subsubsection{Latent heat flux}

The period from DOY348 to DOY365 (December 2003) was selected to show the relevance of changes in $z_{0 m}$. For this, only the dry canopy transpiration was considered, and the result was compared to the case all components of the evaporation were considered. Figure 3 shows that $\lambda E$ simulated using the season-dependent value of $z_{0 m}=0.115 \mathrm{~m}$ corresponding to the selected period produces a more accurate estimation of $\lambda E$ than the fixed value of $z_{0 m} 0.216 \mathrm{~m}$, although both led to an underestimation. The overall MBE related to the use of $z_{0 m}=0.115 \mathrm{~m}$ was $-5 \mathrm{~W} \mathrm{~m}^{-2}$ and $-10 \mathrm{~W} \mathrm{~m}^{-2}$ for $25 z_{0 m}=0.216 \mathrm{~m}$. This was found to be related to the surface exchange coefficient for heat $\left(C_{h}\right)$. In fact, it was noticed that small values of $z_{0 m}$ led to higher $C_{h}$ value and, therefore, to a higher potential evaporation. As the calculation of dry canopy transpiration

\section{HESSD}

3, 2757-2788, 2006

\section{Seasonal dynamics of vegetation covers and land surface models}

F. Bagayoko et al.

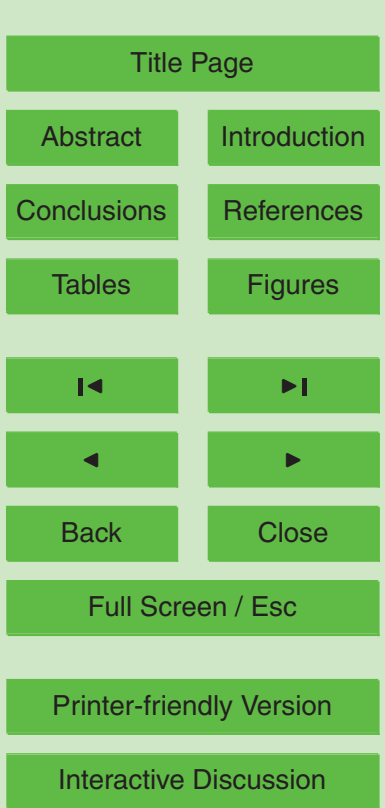

EGU 
is directly related to the potential evaporation by the weighting coefficients, the small values of $z_{0 m}$ will always leads to higher values of the actual evaporation during the dry season, while the other components are neglected. This conclusion is somehow contradictory to the definition of roughness length for momentum. In fact, in the particular 5 case of the vegetation cover, higher values of $z_{0 m}$ mean denser and taller vegetation in contrast to small values of $z_{0 m}$, which should correspond to less a dense and lower vegetation. A higher $z_{0 m}$ should lead, in principle, to a higher actual evaporation for similar vegetation and climatic conditions.

\subsubsection{Sensible heat flux}

10 The sensible heat flux produced similar results to those for the latent heat flux. The season-dependent value of $z_{0 m}=0.115 \mathrm{~m}$ gives a more accurate estimation of the sensible heat flux $\left(\mathrm{MBE}=8 \mathrm{~W} \mathrm{~m}^{-2}\right)$ than the fixed value of $0.216 \mathrm{~m}\left(\mathrm{MBE}=13 \mathrm{~W} \mathrm{~m}^{-2}\right)$ (Fig. 4). Both overestimate the sensible heat flux. The heat exchange coefficient also contributed to this overestimation.

\subsection{Comparison on daily basis (wet period)}

For this part of the analysis, all components of the actual evaporation were considered in the analysis. As during the dry season, the season-dependent value of $z_{0 m}$ gives a more accurate estimation of $\lambda E$ as well as $H$. For $\lambda E$, the model underestimates the observed value for reasons explained in Sect. 4.1 with MBE of $-65 \mathrm{~W} \mathrm{~m}^{-2}$ for $20 \quad z_{0 m}=0.419 \mathrm{~m}$ (seasonal value) and $-71 \mathrm{~W} \mathrm{~m}^{-2}$ for $z_{0 m}=0.216 \mathrm{~m}$ (fixed value) (Fig. 5).

With respect to the sensible heat flux, the model overestimates with $\mathrm{MBE}=0.3 \mathrm{~W} \mathrm{~m}^{-2}$ for $z_{0 m}=0.419 \mathrm{~m}$ (seasonal value) and $5 \mathrm{~W} \mathrm{~m}^{-2}$ for $z_{0 m}=0.216 \mathrm{~m}$ (fixed value) (Fig. 6). The fact that small values of $z_{0 m}$ produce a higher evaporation seems to be compensated by the other components of evaporation. In fact, during the rainy season, the 25 major part of the actual evaporation is the contribution of direct evaporation from the soil and the evaporation of water intercepted by tree leaves.

HESSD

3, 2757-2788, 2006

\section{Seasonal dynamics of vegetation covers and land surface models}

F. Bagayoko et al.

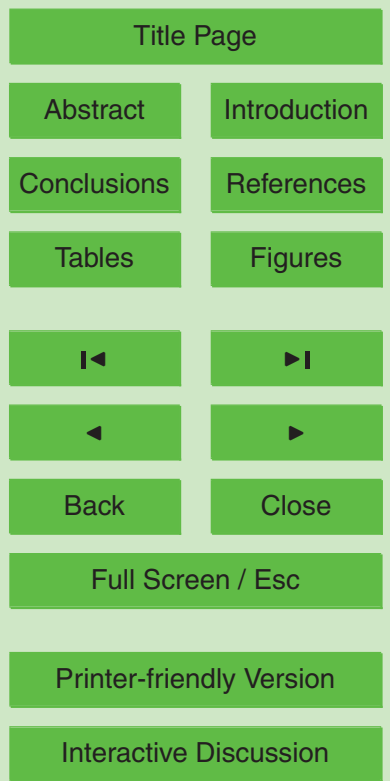

EGU 
In all cases, there was no significant improvement when the simulated fluxes using seasonal values of $z_{0 m}$ were compared to those using a fixed value for all periods. However, the true value of $z_{0 m}$ (seasonal value) seems to be necessary to enhance the performance and the accuracy of the land surface models. The MBE was always 5 weaker when a seasonal value of $z_{0 m}$ was used and appreciably so on a daily basis. Therefore, great attention should be paid to this parameter, and there is a need to take into consideration the seasonal dynamics in the case of a savanna area with intensive agriculture. Even if the area is not subject to agricultural activities, a seasonal bush fire could appreciably change the roughness length for momentum, which stresses the 10 relevance of a deeper analysis of the effect of $z_{0 m}$.

\section{Cause of the insensitivity and proposed improvement}

As previously pointed out, the insensitivity of the NOAH LSM to $z_{0 m}$ is probably related to the formulation of the part of the model that couples the soil and the vegetation to the atmosphere. This coupling is by the coefficient $B_{C}$ explicitly expressed in the dry 15 canopy transpiration (see Eq. 5). $B_{C}$ is a function of the surface exchange coefficient for heat $\left(C_{h}\right)$, which in turn is explicitly expressed as a function of $z_{0 m}$. Therefore, $B_{c}$ was calculated step by step to highlight the part of the formulation that makes it insensitive to $z_{0 m}$. This procedure was started by the surface exchange coefficient $\left(C_{h}\right)$, which was independently calculated with Eq. (6) using the seasonal values of $z_{0 m}$ and a fixed 20 value of $0.216 \mathrm{~m}$. Figure 7 shows that there is a clear difference between both cases. The relative $\operatorname{MBE}\left(\frac{C_{h}\left(z_{0 m}=0.216\right)-C_{h}(\text { seasonal })}{C_{h}\left(z_{0 m}=0.216\right)} \times 100\right)$ was negative during both rainy seasons and positive during the transition periods and dry the season. The higher peaks were observed in August (a period of maximum growth and maximum $z_{0 m}$ ) and were $25 \%$ and $38 \%$ during the rainy season of 2003 and 2004 , respectively. During the dry season and the transition periods, the maximum MBE was $56 \%$ and in March (the driest period corresponding to the weakest value of $\left.z_{0 m}=0.115 \mathrm{~m}\right)$. Similar observations and relative MBE were found for the surface resistance $\left(R_{C}\right)$ estimated by inverting the

\section{HESSD}

3, 2757-2788, 2006

Seasonal dynamics of vegetation covers and land surface models

F. Bagayoko et al.

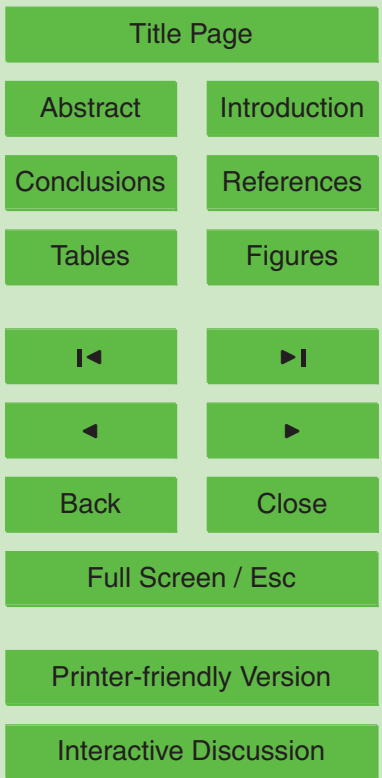

EGU 
Penman-Monteith equation (Monteith, 1965). The inverted equation was preferred because it gave more accurate estimations than the formulation based on NP89. This was related to the use of constant value for moisture in a soil layer, because long-term measurements were not available. In fact, Huntingford et al. (1994) mentioned that in 5 the Sahelian savanna, nothing is to be gained by using more complicated models than a Big Leaf Model based on inverting the Penman-Monteith equation.

When $B_{c}$ was calculated, it was seen that the net difference observed in $C_{h}$ and $R_{C}$ was significantly reduced. The relative MBE value were now positive and weaker during the rainy seasons $(0.82 \%$ and 1.33 in 2003 and 2004, respectively), and negative 10 during the dry season and the transition periods (the higher absolute value was $7 \%$ and was found in March) (Fig. 8). The weakness of the relative MBE and its inversion were found to be related to the product $R_{c} \times C_{h}$ in the denominator of the equation expressing $B_{c}$. This product annihilates the effect of the use of seasonal values and the fixed value of $z_{0 m}$ on $C_{h}$ and $R_{c}$ (Fig. 8). Therefore, the product $R_{c} \times C_{h}$ is the major 15 cause of the insensitivity of NAOH LSM to $z_{0 m}$. The proposed formulation is based on a principle similar to that used in the Penman-Monteith equation. The principle is that the dry canopy transpiration decreases with increasing surface resistance $\left(R_{c}\right)$ and aerodynamic resistance [s $\mathrm{m}-1$ ] . Therefore, the new formulation is expressed as follows:

$B_{\text {cnew }}=\alpha\left(\frac{1+\frac{\Delta}{R_{r}}}{1+\left(R_{c}+R_{a}\right)+\frac{\Delta}{R_{r}}}\right)$

where $\alpha$ is the coefficient of adjustment of $B_{c \text { new }}$ to $B_{c}$. The value of $\alpha$ was set to 22.31 $\left[\mathrm{s} \mathrm{m}^{-1}\right]$ and the optimum value obtained using the least square minimisation approach. This value of $\alpha$ overestimated the original $B_{C}$ during the rainy season $\mathrm{MBE}=0.13 \mathrm{~m} \mathrm{~s}^{-1}$ and underestimated during the dry season $\left(\mathrm{MBE}=-0.19 \mathrm{~m} \mathrm{~s}^{-1}\right)$. The overall MBE was $25-0.11 \mathrm{~m} \mathrm{~s}^{-1}$ on a season-basis. Important is to notice here is that $B_{c n e w}$ clearly produces differences between the seasonal based $z_{0 m}$ and fixed value of $0.216 \mathrm{~m}$ (Fig. 9). When $B_{c \text { new }}$ was introduced in the NOAH LSM program, its performance was improved.
HESSD

3, 2757-2788, 2006

Seasonal dynamics of vegetation covers and land surface models

F. Bagayoko et al.

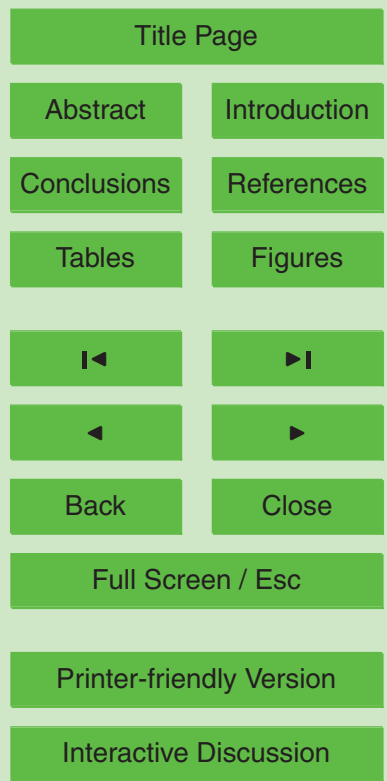

EGU 
The bias error was greatly reduced when compared to the bias error of the original model (Fig. 10). Therefore, the adoption of the proposed formulation of $B_{c}$ can be recommended.

HESSD

3, 2757-2788, 2006

\section{Seasonal dynamics of vegetation covers and land surface models} basis. Therefore, when this model is kept in the standard form, a suitable fixed value of $z_{0 m}$ could be sufficient to simulate reasonably the seasonal dynamics of the surface fluxes over the savanna region in West Africa. However, this analysis shows that the 10 different values of $z_{0 m}$ should give, in principle, different outputs for the surface fluxes. This was justified by the significant difference observed in the surface exchange coefficient for the heat and the surface resistance when applying the season-based $z_{0 m}$ and a fixed value of $z_{0 m}$. The results of the investigation show that the insensitivity of the NOAH LSM with respect to $z_{0 m}$ was related to the formulation of the coefficient $B_{c}$, 15 which couples the soil and the vegetation to the atmosphere. In the formulation of $B_{C}$, the product $C_{h} \times R_{C}$ was found to be the main cause for this. A new formulation of $B_{C}$ is proposed to remediate the insensitivity, which appreciably improved the performance of the model.

Further problems arose with respect to the underestimation of observed latent flux, 20 especially during the rainy and dry period. The use of a constant value for soil moisture, leaf area index and minimum resistance appeared to be the reason these findings. It is recommended to introduce a seasonal variation of the variables as a first improvement. More research should be undertaken to formulate the relationship between the minimum resistance and the seasonal moisture variability, because the savanna vegetation is very sensitive to any variation in soil moisture. Similar recommendations are
F. Bagayoko et al.

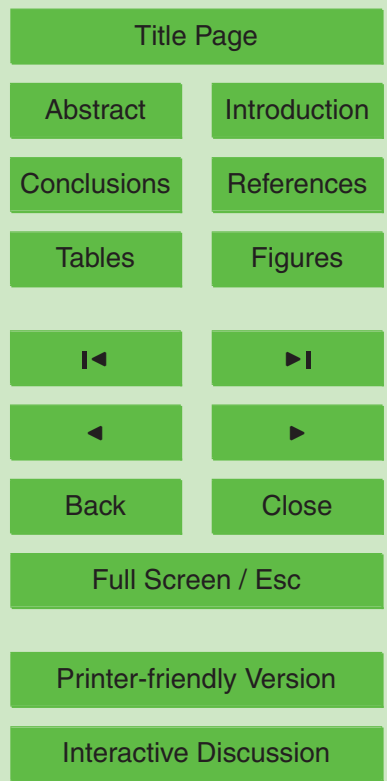

EGU given by Schüttemeyer (2005). If seasonal data are not available, some simplifications could be made for the case of savanna zone submitted to intensive agriculture. The 
first simplification could be the subdivision of the annual cycle in three large ranges: the rainy season (June to October), the transition periods (October to December, April to June) and the completely dry period (January to April), where a constant value of soil moisture, leaf area index, the minimum resistance, albedo and the roughness length

5 for momentum could be adequate for each period. This recommendation is justified by the fact that on farmland, two homogenous situations are generally encountered. During the growing periods, the terrain dominated by crops and sparse trees, the crop minimum resistance could be used, and the leaf area index and the roughness length momentum can be related to the development stage of crops. Well defined relationships between crop height, leaf area index and roughness length are available in the literature (Brutsaert, 1982; Oguntunde, 2004). The initial moisture condition of the soil layer can also be kept constant because of the regular rain during that period. The second homogenous period is the period after the harvest. The terrain is then dominated by bare soil and sparse trees. During that period, the tree minimum resistance could 15 be used. Roughness length for momentum, leaf area index and soil moisture could also be kept constant. For all these periods, some point measurements of the needed variables could be carried out, and more time consuming long-term investigations can be avoided. For the transition periods, the recommendations of Schüttemeyer (2005) are suitable. Similar recommendations are also made fro terrain without agricultural 20 activities.

Another important point is the use of all components of the actual evaporation during the drying and the completely dry period. This led to an overestimation of the observed fluxes when the standard form of the NOAH LSM but as soon as the direct evaporation from the soil and the wet canopy was neglected, some adjustment of the dry canopy transpiration became necessary. This overestimation was greatly reduced when the proposed formulation of $B_{C}$ was introduced.

The estimation of the canopy resistance of the inverted Penman-Monteith equation seems to be more realistic, because the formulation based on NP89 leads to an underestimation during the dry period and to an overestimation during the rainy season.

HESSD

3, 2757-2788, 2006

Seasonal dynamics of vegetation covers and land surface models

F. Bagayoko et al.

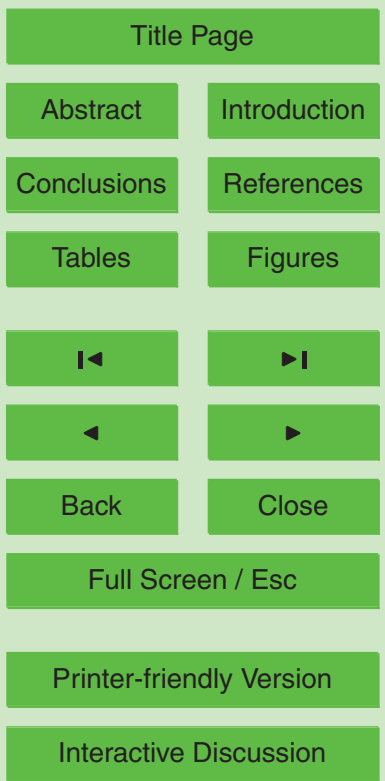


Acknowledgements. The authors are grateful to the Center for Development Research (ZEF) of Bonn University, I'Institut de l'Environement et de la Recherche Agricole (INERA) of Burkina Faso and Groupe EIER-ESTHER, which provided the field and office facilities. This study was performed in the framework of the VINVAI Project (EU-INCO Contract ICA4-CT-2001-10047)

5 with additional support from the GLOWA Volta project. J. Elbers is specially thanked for his support regarding the eddy covariance equipment.

\section{References}

Brutsaert, W.: Evaporation into the atmosphere: Theory, History, and Application. Kluwer, Boston, 299, 1982.

Chen, F., Janjic, D., Yang, Z., and Mitchell, K.: Impact of atmospheric surface-layer parametrizations in the new Land Surface Scheme of the NCEP mesoscale Eta model, J. Appl. Meteor., 38, 405-422, 1997.

Chang, S., Hahn, D., Yang, C.-H., Norquist, D., and Ek, M.: Validation Study of the CAPS Model Land Surface Scheme Using the 1987 Cabauw/PILPS Dataset, J. Appl. Meteor., 38, 31-39, 151999

Ek, M. and Holtslag, A. A. M.: Influence of Soil Moisture on Boundary Cloud Development, J. Hydrometeor., 5, 86-99, 2004.

Ek, M. and Mahrt, L.: A formulation for boundary-layer cloud cover, Ann. Geophys., 9, 716724, 1991.

Goutorbe, J. P., Dolman, A. J., and Gash, J. H. C.: HAPEX-Sahel: a large scale study of land atmosphere interactions in the semiarid tropics, Ann. Geophys., 12, 53-64, 1997.

Huntingford, S. J., Allen, R. J., and Harding, R. J.: An intercomparison of single and dual-source vegetation-atmosphere transfer models applied to transpiration from Sahelian Savannah, 1994.

Idso, S. B. and Jackson, R. D.: Thermal radiation from the atmosphere, J. Geophys. Res., 74, 5397-5403, 1967.

Jacquemin, B. and Noilhan, J.: Sensitivity study and validation of land-surface parameterization using the HAPEX-MOBHILY data set, Bound.-Layer Meteor., 52, 93-134, 1990.

Jarvis, P.: The interpretation of the variations in leafwater potentials and stomatal conductances found in canopies in the field, Philos. Trans. R. Soc. London, Ser. B 273, 593-610, 1976.

HESSD

3, 2757-2788, 2006

\section{Seasonal dynamics of vegetation covers and land surface models}

F. Bagayoko et al.

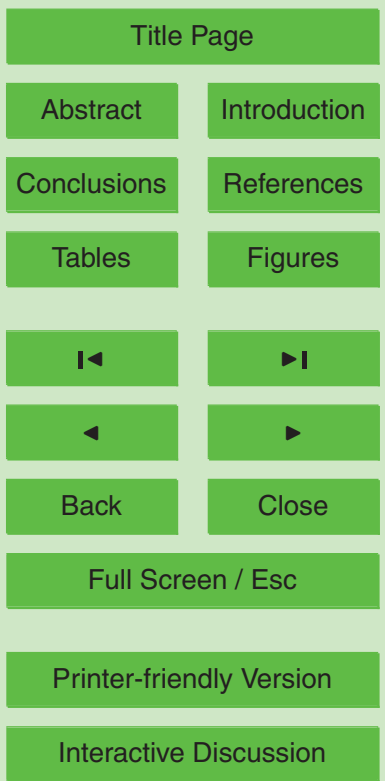

EGU 
Mahrt, L. and Ek, M.: The influence of the atmospheric stability on the potential evaporation, J. Clim. Appl. Meteorol., 23, 222-234, 1984.

Martano, P.: Estimation of surface roughness length and displacement heigth from single-level sonic anemometer data, J. Appl. meteorol., 39, 708-715, 1999.

5 Monteith, J. L.: Evaporation and the environment, Symp. Soc. Expl. Biol., 19, 205-234, 1999.

Niyogi, D. S., Xue, Y., Raman, S., and Alapaty, K.: Uncertainty in the Specification of Surface Characteristics, Part ii: Hierarchy of Interaction-Explicit Statistical Analyis, Boundary Layer Meteor., 91, 341-366, 1999.

Noilhan, J. and Planton, S.: A simple parametrization of the land surface processes for meteorological models, Mon. Wea. Res., 117, 536-549, 1989.

Jacquemin, B. and Noilhan, J.: Sensitivity study and validation of land-surface parametrization using the HAPEX-MOBHILY data set, Bound-Lay. Meteor., 52, 93-134, 1990.

Oguntunde, P. G.: Evapotranspiration and complementarity relations in the water balance of the Volta Basin: Field measurements and GIS-Based regional estimates, ZEF Bonn, Bonn, 15169 pp., 2004.

Pan, H.L. and Mahrt, L.: Interaction between soil hydrology and boundary-layer development, Bound-Lay. Meteorol., 38, 185-202, 1986.

Schüttemeyer, D.: The surface energy balance over drying semi-arid terrain in West Africa, University of Wageningen, The Netherlands, 154 pp., 2005.

20 Sellers, P. J., Randall, D. A., Collatz, G. J., Berry, J. A., Field, C. B., Dazlich, D. A., Zhang, C., Callelo, G. D., and Bounoua, L.: A revised land surface parameterization (SiB2) for atmospheric GCMs, Partl: Model formultion, J. Climate, 9, 676-705, 1996.

Stewart, J. B.: Modelling surface conductance of pine forest, Agric. For. Meteorol., 43, 19-35, 1988.

Ungaro, F., Quaglino, E., Gallorini, D., and Pestarini, M.: Physical and hydrological properties of soils on three inland valleys of Ghana (Kumassi region) and Burkina Faso (Kompienga region), Research Report, VinVal, Timesis, Italy, 2004.

van de Giesen, N. C., Kunstman, H., Jung, G., Liebe, J., Andreini, M., and Vlek, P.: The GLOWA-Volta project: Integrated assessment of feedback mechanisms between climate,

30 land-use, and hydrology, Advance in Global Change Research, 10, 165-175, 2002.

Zeng, X., Dai, Y.-J., Dickinson, R. E., and Shaikh, M.: The role of root distribution for climate simulation over land, Geophy. Res. Lett., 25, 4533-4536, 1998.

Zilitinkevich, S. S.: Non-local turbulent transport: pollution dispersion aspects of the coherent

HESSD

3, 2757-2788, 2006

\section{Seasonal dynamics of vegetation covers and land surface models}

F. Bagayoko et al.

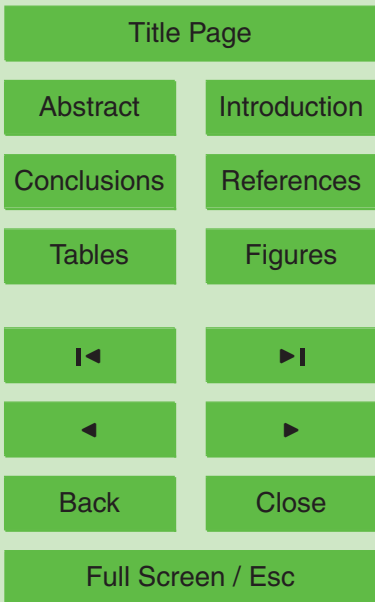

Printer-friendly Version

Interactive Discussion 
structure of convective flow, in: Air Pollution III - Volume I, Air Pollution Theory and Simulation, edited by: Power, H., Moussiopoulos, N., and Brebbia, C. A., Computational Mechanics Publication, Southampton Boston, 53-60, 1995.

\section{HESSD}

3, 2757-2788, 2006

\section{Seasonal dynamics of vegetation covers and land surface models}

F. Bagayoko et al.

Title Page

Abstract Introduction

Conclusions References

Tables Figures

14

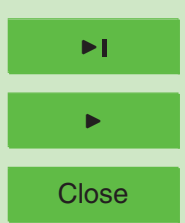

Back

Full Screen / Esc

Printer-friendly Version

Interactive Discussion 


\section{HESSD}

Table 1. Model parameter values for modified NOAH LSM.

3, 2757-2788, 2006

\section{Seasonal dynamics of vegetation covers and land surface models}

\begin{tabular}{|c|c|c|c|}
\hline \multicolumn{4}{|l|}{ General parameters } \\
\hline Vegetation fraction & $\alpha_{\mathrm{V}}$ & See Table 2 & {$[-]$} \\
\hline Albedo & $\alpha$ & & {$[-]$} \\
\hline Maximum canopy interception capacity & $\mathrm{S}$ & 0.50 & $\mathrm{~mm}$ \\
\hline Roughness length for momentum & $\mathrm{z}_{0 \mathrm{~m}}$ & See Table 2 & $\mathrm{~m}$ \\
\hline Roughness length for heat & $\mathrm{z}_{0 \mathrm{~h}}$ & & $\mathrm{~m}$ \\
\hline Soil moisture at field capacity & $\theta_{\mathrm{fc}}$ & 0.32 & $\mathrm{~m}^{3} \mathrm{~kg}^{-1}$ \\
\hline Soil moisture at wilting point & $\theta_{\mathrm{wp}}$ & 0.01 & $\mathrm{~m}^{3} \mathrm{~kg}^{-1}$ \\
\hline Soil porosity & & & $\%$ \\
\hline Maximum canopy resistance & $\mathrm{R}_{\mathrm{cmax}}$ & 5000.00 & $\mathrm{~s} \mathrm{~m}^{-1}$ \\
\hline Minimum canopy resistance & $\mathrm{R}_{\mathrm{cmin}}$ & 18.00 & $\mathrm{~s} \mathrm{~m}^{-1}$ \\
\hline Leaf area index & LAI & 3.00 & {$[-]$} \\
\hline $\mathrm{R}_{\mathrm{GL}}$ & & 30 for trees and 100 for crops (Jacquemin and Noilhan, 1990) & $\mathrm{W} \mathrm{m} \mathrm{m}^{-2}$ \\
\hline$g_{\mathrm{D}}$ & & 36.7 (Huntingford et al., 1995) for savannah & $\mathrm{g} \mathrm{kg}^{-1}$ \\
\hline Thermal coefficient & $\mathrm{a}_{\mathrm{T}}$ & 0.0016 (Ek and Holtslag, 2004) & $\mathrm{K}^{-2}$ \\
\hline Reference temperature & Tref & 298 (Jacquemin and Noilhan, 1990) & $\mathrm{K}$ \\
\hline Root distribution over 4 layers (Schüttemeyer, 2005) & $27 ; 37 ; 27 ; 9 ; 34 ; 27,14$ & & $\%$ \\
\hline \multicolumn{4}{|l|}{ Atmospheric forcing data } \\
\hline Air temperature & $\mathrm{T}_{\mathrm{a}}$ & & $\mathrm{K}$ \\
\hline Relative humidity & $\mathrm{R}_{\mathrm{h}}$ & & $\%$ \\
\hline Surface pressure & $\mathrm{P}_{\mathrm{s}}$ & & mbar \\
\hline Wind speed & $\mathrm{u}$ & & $\mathrm{m} \mathrm{s}^{-1}$ \\
\hline Surface downward longwave radiation & $\mathrm{R}_{\mathrm{sL}}$ & & $\mathrm{W} \mathrm{m} \mathrm{m}^{-2}$ \\
\hline Solar radiation & $\mathrm{R}_{\mathrm{s}}$ & & $\mathrm{W} \mathrm{m} \mathrm{m}^{-2}$ \\
\hline Precipitation & $\mathrm{P}$ & & $\mathrm{mm}$ \\
\hline
\end{tabular}

\section{F. Bagayoko et al.}

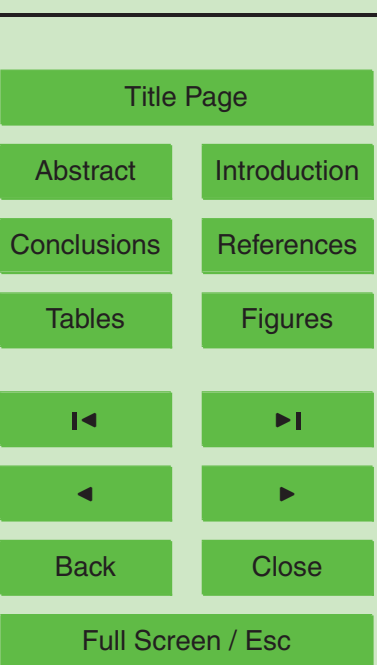

Printer-friendly Version

Interactive Discussion 


\section{HESSD}

3, 2757-2788, 2006

Table 2. Season-dependent vegetation fraction $\left(\alpha_{V}\right)$ and albedo $(\alpha)$ and roughness length for momentum $\left(z_{0 m}\right)$.

\begin{tabular}{lccr}
\hline Month of the year & Vegetation fraction & Albedo & $\mathrm{z}_{0 \mathrm{~m}}$ \\
\hline January & 0.04 & 0.22 & 0.14 \\
February & 0.02 & 0.27 & 0.13 \\
March & 0.05 & 0.3 & 0.11 \\
April & 0.08 & 0.25 & 0.14 \\
May & 0.24 & 0.24 & 0.22 \\
June & 0.4 & 0.24 & 0.20 \\
July & 0.47 & 0.26 & 0.27 \\
August & 0.56 & 0.25 & 0.42 \\
September & 0.61 & 0.26 & 0.32 \\
October & 0.51 & 0.22 & 0.25 \\
November & 0.3 & 0.23 & 0.14 \\
December & 0.12 & 0.23 & 0.12 \\
\hline
\end{tabular}

Seasonal dynamics of vegetation covers and land surface models

F. Bagayoko et al.

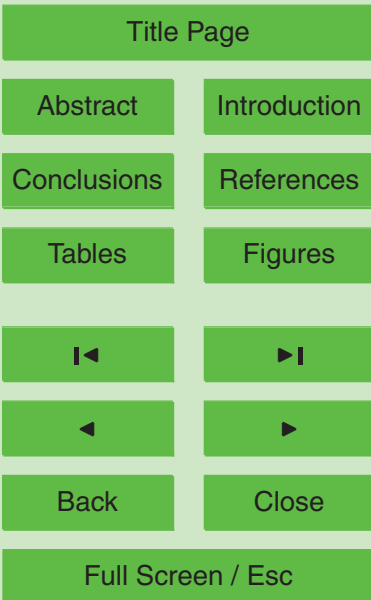

Printer-friendly Version

Interactive Discussion 


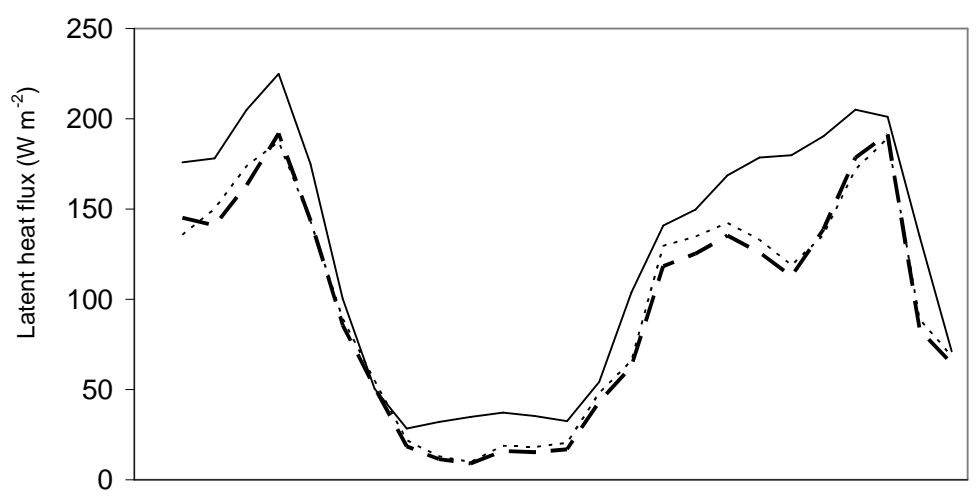

HESSD

3, 2757-2788, 2006

\section{Seasonal dynamics of vegetation covers and land surface models}

F. Bagayoko et al.

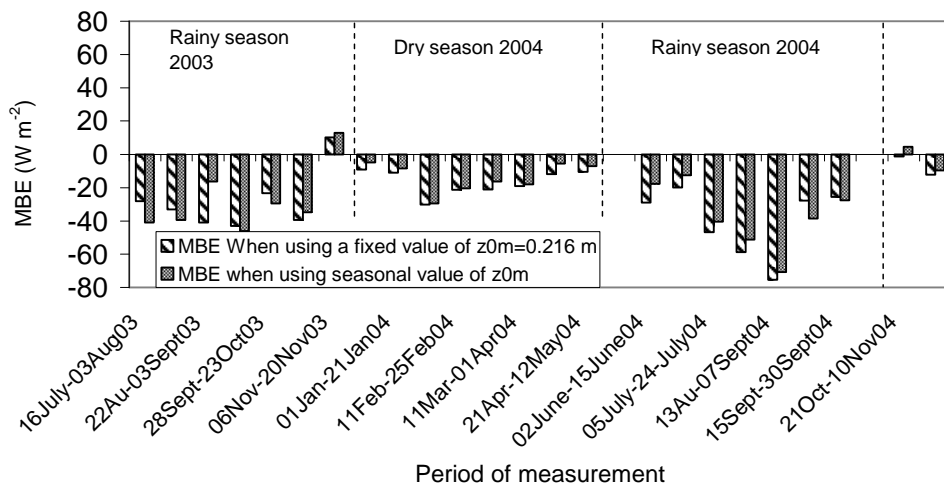

Title Page

Abstract Introduction

Conclusions

References

Tables

Figures

14

>I

4

Back

Close

Full Screen / Esc

Fig. 1. Comparison between the observed and simulated latent heat flux on a seasonal basis. The solide line corresponds to the measured latent flux, the bold dashed line corresponds to the simulated latent heat using a fixed value of $z_{0 m}$, while the light dashed line corresponds to the simulated latent heat flux using the seasonal values of $z_{0 m}$.

Printer-friendly Version

Interactive Discussion 


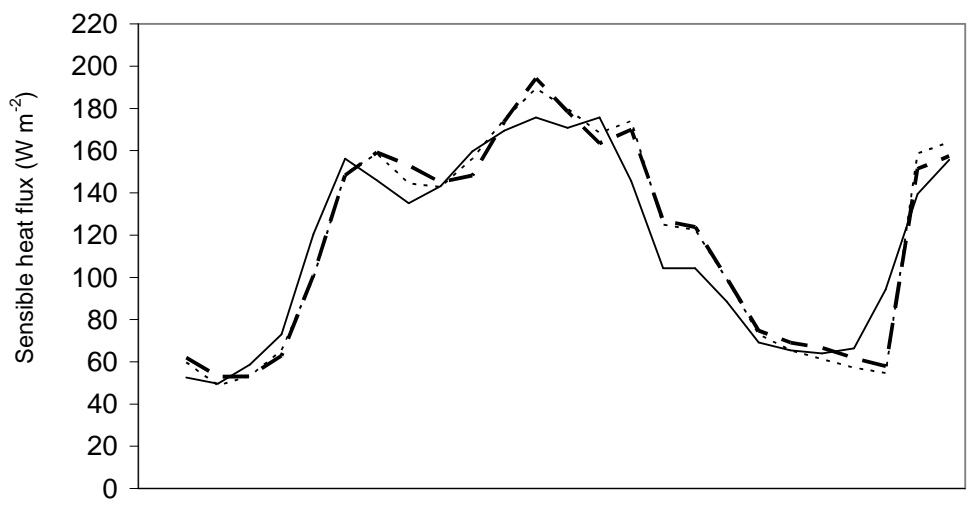

HESSD

3, 2757-2788, 2006

\section{Seasonal dynamics of vegetation covers and land surface models}

F. Bagayoko et al.

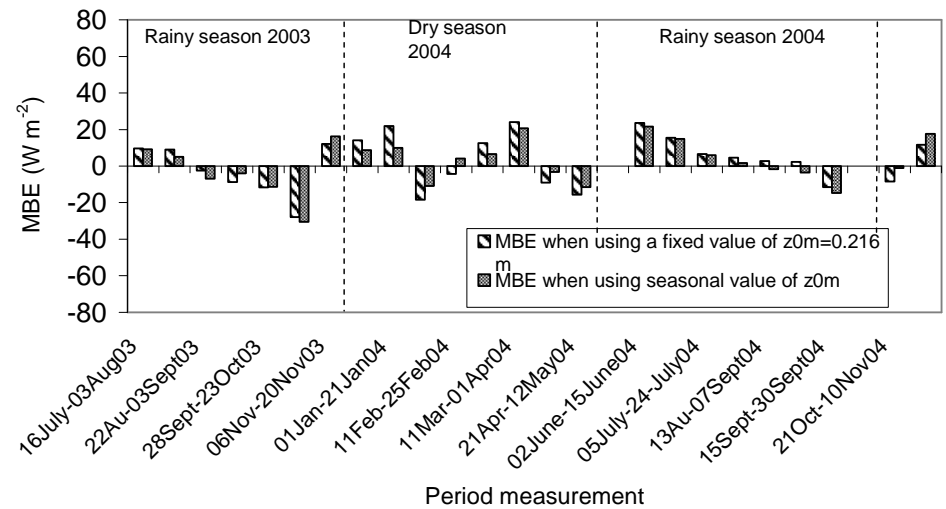

Title Page

Abstract

Conclusions

Tables

14

4

Back
Introduction

References

Figures

$\rightarrow$

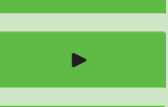

Close

Fig. 2. Comparison between observed and simulated sensible heat flux on a seasonal basis. The solide line corresponds to the measured sensible heat flux, the bold dashed line corre-

Full Screen / Esc sponds to the simulated sensible heat using a fixed value of $z_{0 m}$, while the light dashed line corresponds to the simulated sensible heat flux using the seasonal values of $z_{0 m}$.

Printer-friendly Version

Interactive Discussion 


\section{HESSD}

3, 2757-2788, 2006

\section{Seasonal dynamics of vegetation covers and land surface models}

F. Bagayoko et al.

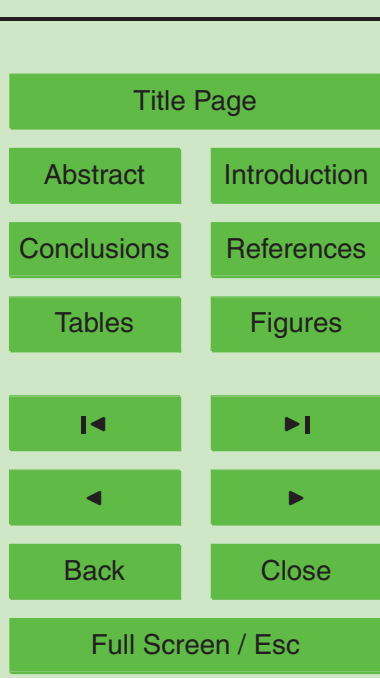

Printer-friendly Version 


\section{HESSD}

3, 2757-2788, 2006

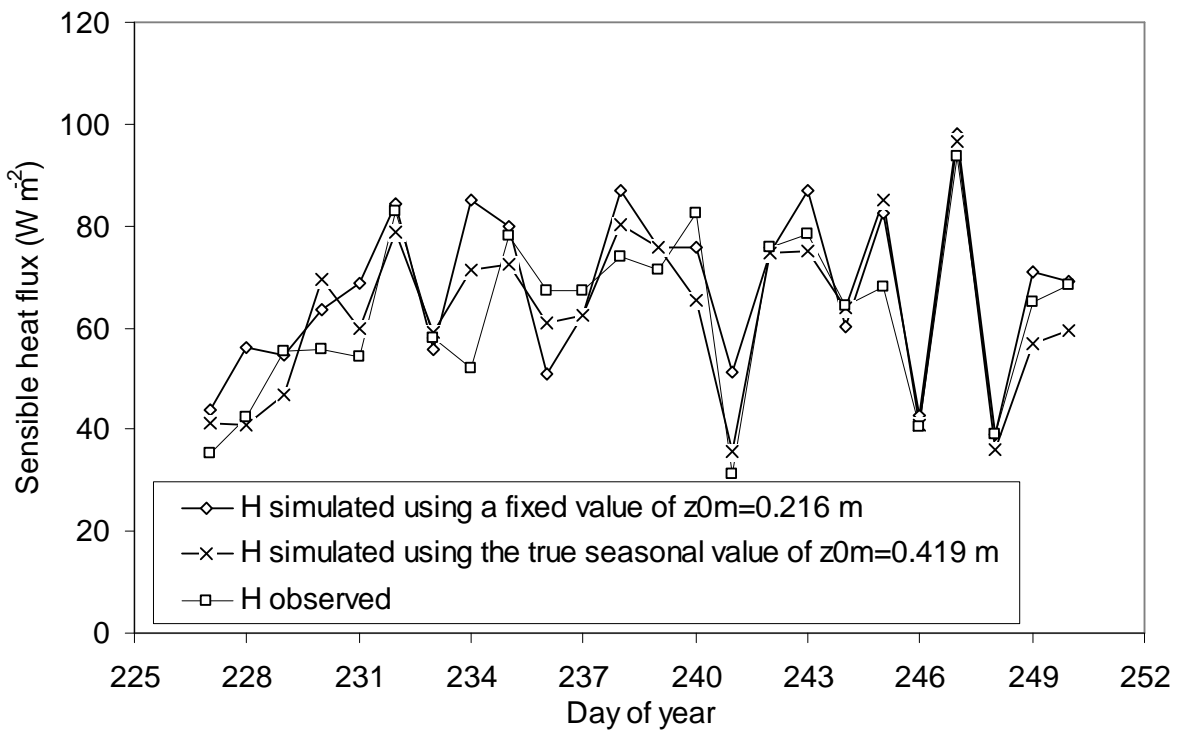

\section{Seasonal dynamics of vegetation covers and land surface models}

F. Bagayoko et al.

\section{Title Page}

Abstract

Conclusions
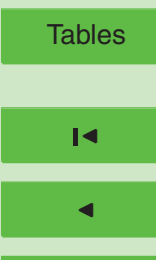

Back
Introduction

References

Figures

$\rightarrow$ I

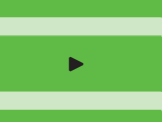

Close DOY 365 . 


\section{HESSD}

3, 2757-2788, 2006

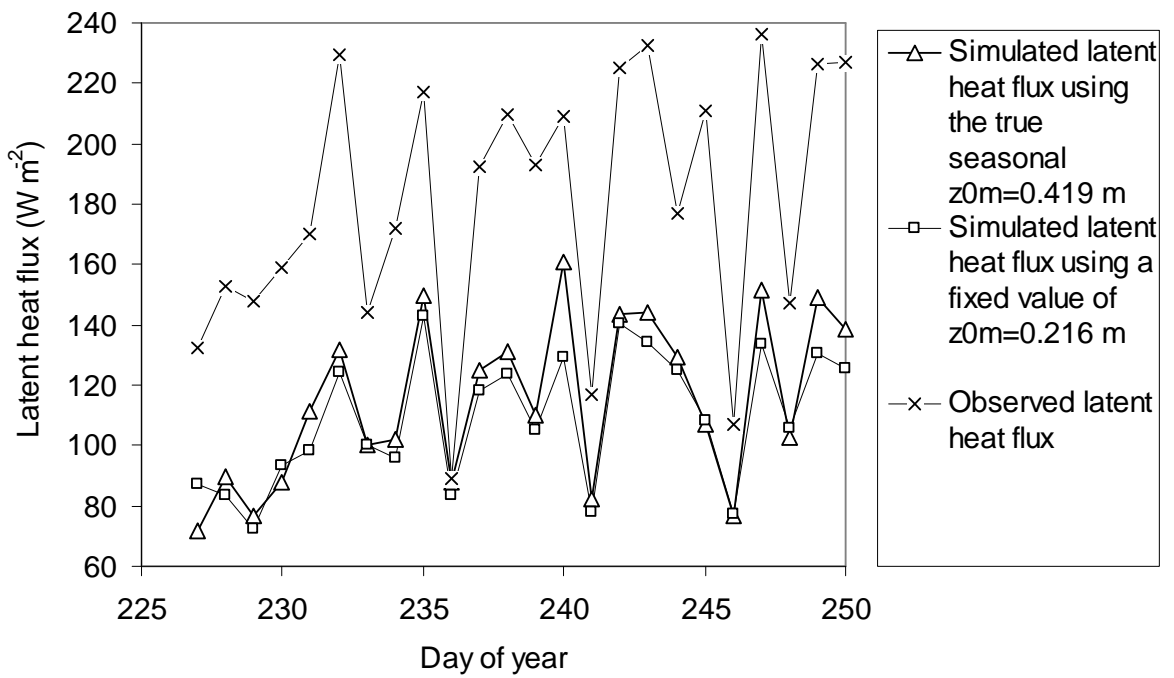

\section{Seasonal dynamics of vegetation covers and land surface models}

F. Bagayoko et al.

Title Page

Abstract

Conclusions
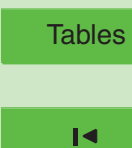

4

Back

\section{Introduction}

References

Figures

।

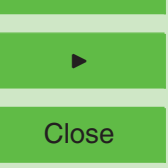

Full Screen / Esc

Printer-friendly Version 


\section{HESSD}

3, 2757-2788, 2006

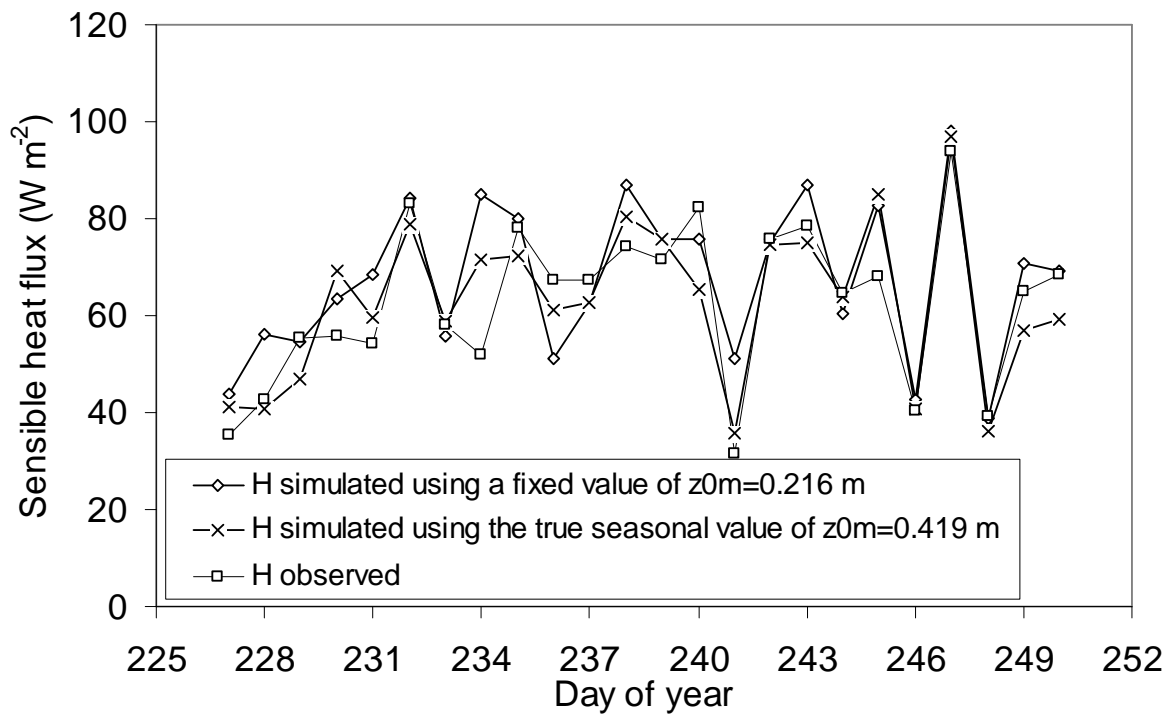

Seasonal dynamics of vegetation covers and land surface models

F. Bagayoko et al.

Title Page

Abstract

Introduction

Conclusions

References

Tables

Figures

14

$>$ I

4

Back

Close

Full Screen / Esc

Printer-friendly Version

Interactive Discussion 


\section{HESSD}

3, 2757-2788, 2006

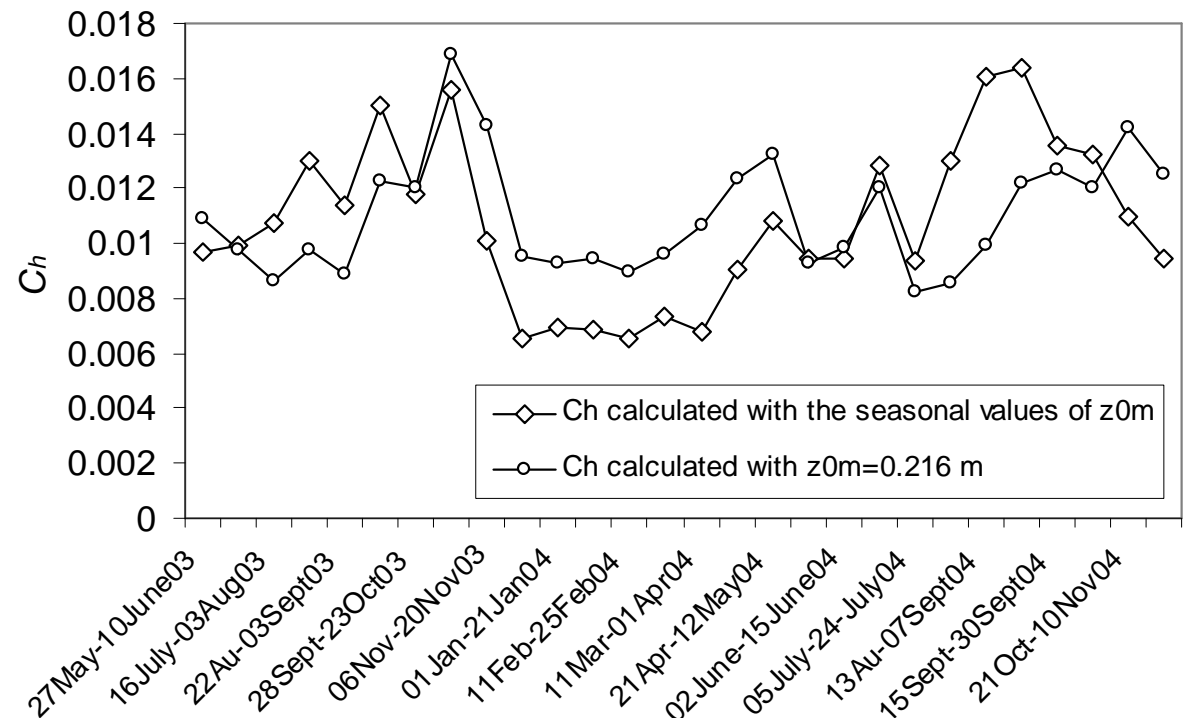

Fig. 7. Comparison between the surface exchange coefficients for heat calculated with the seasonal values of $z_{0 m}$ and with a fixed value of $0.216 \mathrm{~m}$.

\section{Seasonal dynamics of vegetation covers and land surface models}

F. Bagayoko et al.

Title Page

Abstract

Introduction

Conclusions

References

Tables

Figures

14

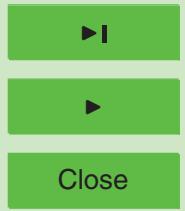

Back

Full Screen / Esc

Printer-friendly Version 


\section{HESSD}

3, 2757-2788, 2006

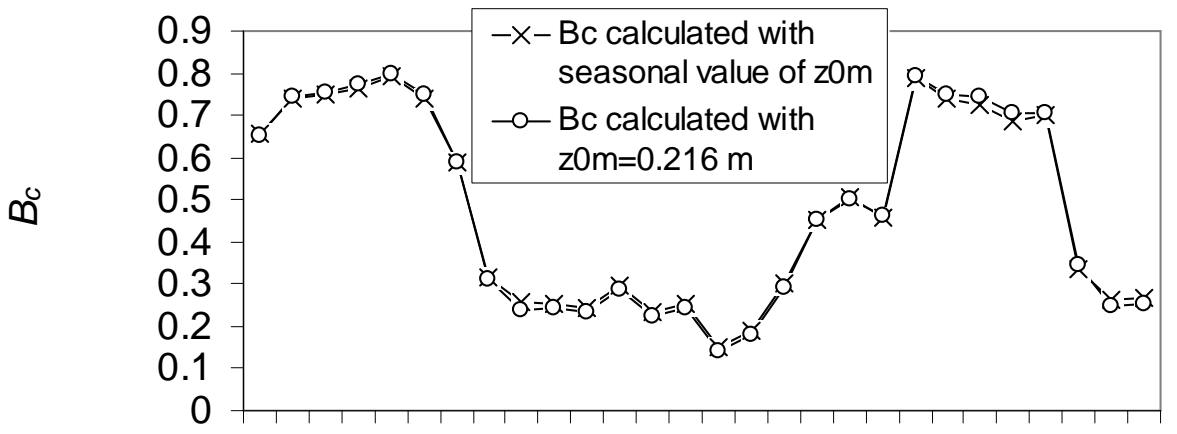

\section{Seasonal dynamics of vegetation covers and land surface models}

\section{F. Bagayoko et al.}

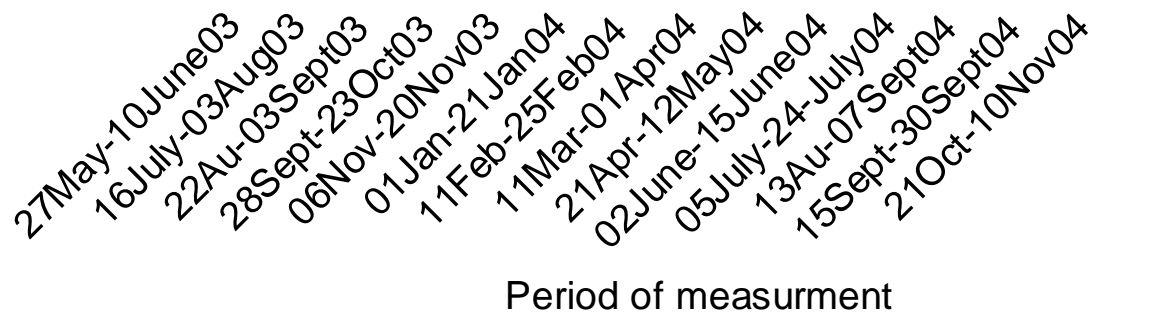

Fig. 8. Comparison between $B_{c}$ calculated with the original formulation using a fixed and seasonal true value of $z_{0 m}$.

Title Page

Abstract

Introduction

Conclusions

References

Tables

Figures

14

$\rightarrow 1$

4

Full Screen / Esc

Printer-friendly Version 


\section{HESSD}

3, 2757-2788, 2006

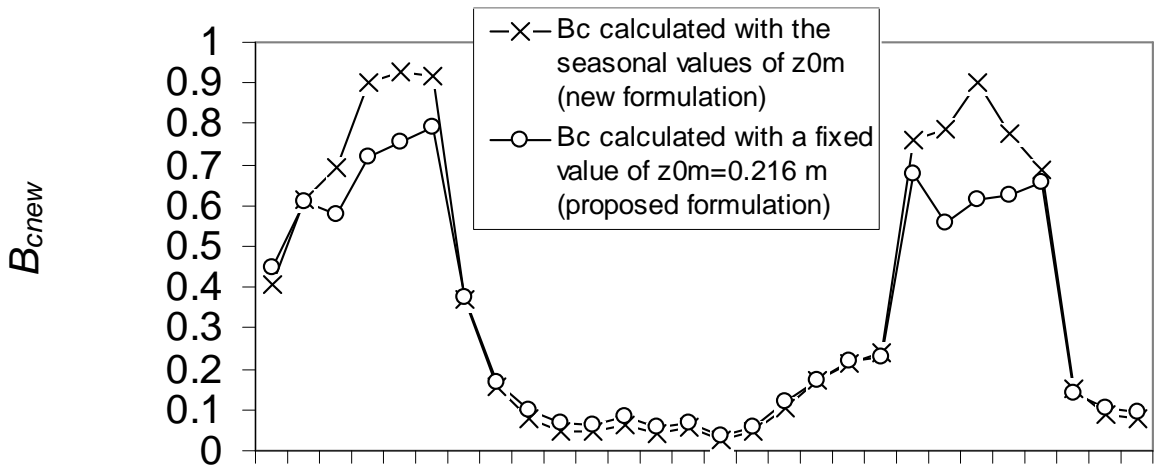

\section{Seasonal dynamics of vegetation covers and land surface models}

F. Bagayoko et al.

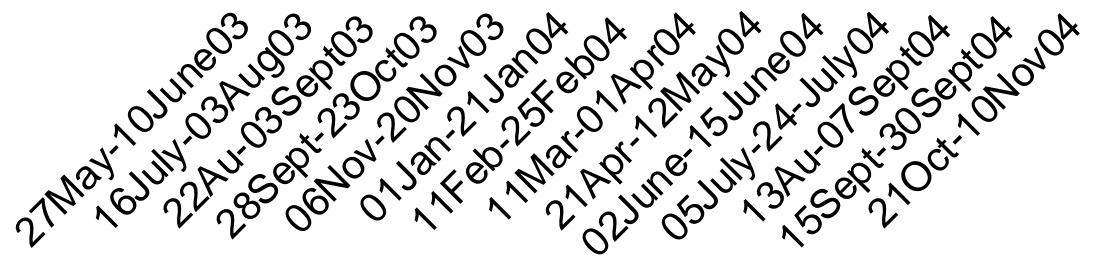

Fig. 9. Comparison between $B_{C}$ calculated with the proposed formulation using a fixed and seasonal true value of $z_{0 m}$.

Title Page

Abstract

Introduction

Conclusions

References

Tables

Figures

14

DI

4

Full Screen / Esc

Printer-friendly Version 

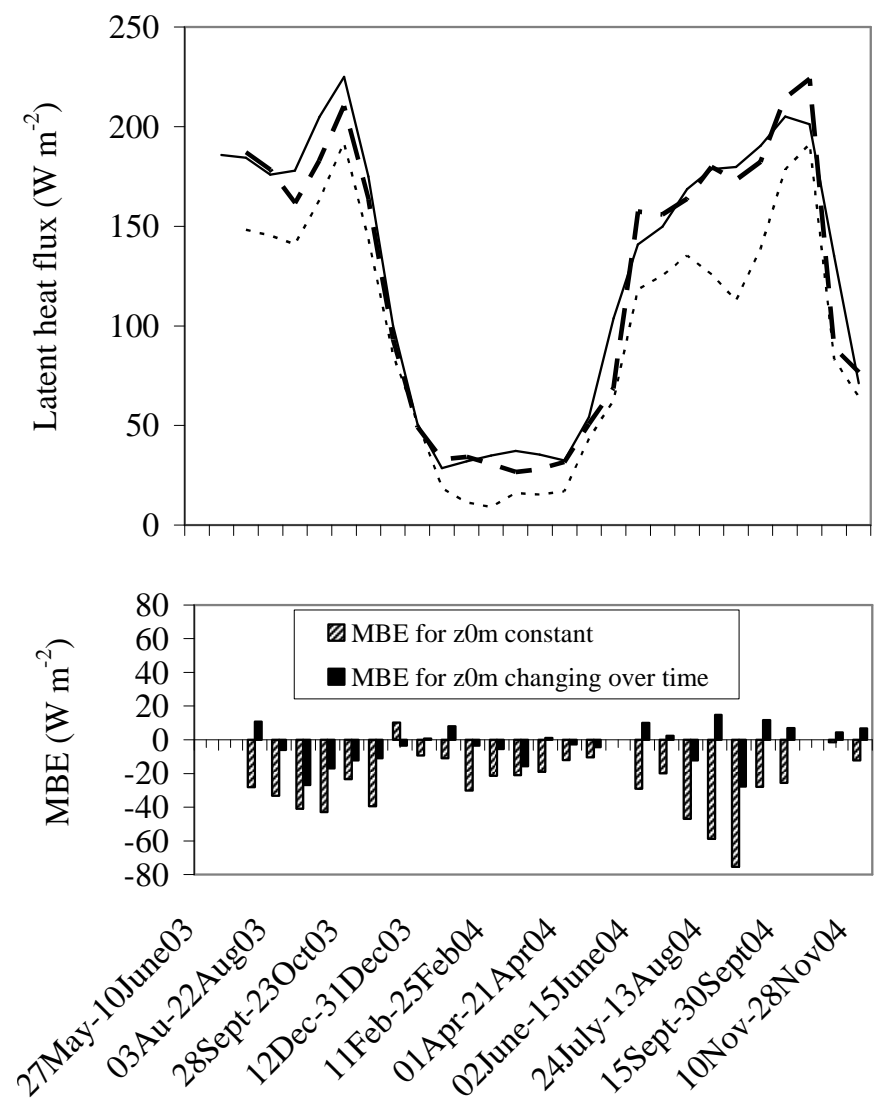

Period of measurement

Fig. 10. Comparison between the performance of the standard (dashed line) and the improved NOAH LSM (bold dashed line). The solide line corresponds to the observed latent heat flux.

\section{HESSD}

3, 2757-2788, 2006

\section{Seasonal dynamics of vegetation covers and land surface models}

F. Bagayoko et al.

Title Page

Abstract

Introduction

Conclusions

References

Tables

Figures

14

- I

4

Back

Close

Printer-friendly Version

Interactive Discussion 